\title{
O Minecraft na formação de professores dos anos iniciais em matemática
}

\author{
Adriana Fernandes do Carmo ${ }^{1}$ \\ Karine Gabrielle Fernandes ${ }^{2}$ \\ Marcela Arantes Meirelles ${ }^{3}$ \\ Reginaldo Fernando Carneiro ${ }^{4}$
}

\section{Resumo}

Neste relato de experiência, discutiremos algumas possibilidades da utilização do jogo Minecraft na formação de professores dos anos iniciais, referente à matemática. Essa temática surgiu da demanda dos participantes de um projeto de pesquisa e extensão ao refletir sobre o ensino e a aprendizagem de ciências e matemática. Desenvolveram-se oficinas que possibilitaram discutir jogos eletrônicos e conteúdos matemáticos que poderiam ser abordados com o Minecraft. Devido a falta de familiaridade com o jogo, ele foi utilizado somente em alguns momentos quando aprendemos sobre sua dinâmica e depois seus conceitos foram explorados de forma lúdica e concreta. Constatamos a importância da visualização em geometria e a possibilidade de desenvolver, por exemplo, estratégias para resolução de problemas.

Palavras-chave: Minecraft; Formação de professores; Matemática; Anos iniciais.

\section{The Minecraft in the teacher education of early years in mathematics}

\begin{abstract}
We aim, in this experience report, to discuss some possibilities of the use of Minecraft in teacher education of the early years with regard to mathematics. This theme has arisen from the demand of participants in a research and extension project to reflect on the teaching and learning of science and mathematics. Workshops on Minecraft were developed, which enabled the discussion of electronic games and mathematical content that could be approached with it. Due to the lack of familiarity with the game, it was only used in a few moments when we learned about it dynamics and then their concepts were explored in a playful and concrete way. We noted the importance of visualization in geometry and the possibility to develop, for example, strategies for the problems resolution. Keywords: Minecraft. Teacher education. Mathematics. Early years.
\end{abstract}

\section{Introdução}

A formação de professores que ensinam matemática nos anos iniciais do Ensino Fundamental tem sido abordada em pesquisas que discutem os mais diferentes aspectos

\footnotetext{
${ }^{1}$ Colégio de Aplicação João XXIII. Juiz de Fora/MG. Endereço eletrônico: fernandes.adriana@ufjf.edu.br ${ }^{2}$ Universidade Federal de Juiz de Fora. Juiz de Fora/MG. Endereço eletrônico: karinegfe@gmail.com ${ }^{3}$ Universidade Federal de Juiz de Fora. Juiz de Fora/MG. Endereço eletrônico: marcela.a.meirelles@hotmail.com ${ }^{4}$ Universidade Federal de Juiz de Fora. Juiz de Fora/MG. Endereço eletrônico: reginaldo.carneiro@ufjf.edu.br
}

$$
\text { Periódico Horizontes - USF - Itatiba, SP-Brasil - e019015 }
$$


referentes a essa temática. Como uma maneira de contribuir com essas discussões, desenvolvemos desde 2015 um projeto de pesquisa e extensão intitulado "Práticas docentes em ciências e matemática de professores dos anos iniciais em início de carreira", financiado pela Fundação de Amparo à Pesquisa de Minas Gerais - FAPEMIG - e pela Pró-Reitoria de Extensão da Universidade, com o objetivo de compreender as práticas docentes de professores iniciantes dos anos iniciais do Ensino Fundamental, no processo de aprender e de ensinar ciências e matemática.

Para tanto, temos um grupo de estudos que se reúne quinzenalmente na Faculdade de Educação da Universidade e do qual participam licenciandos em Pedagogia, Matemática e Química, estudantes de Pós-Graduação, professores dos anos iniciais e pesquisadores. Compreendemos que a diversidade de olhares dos diferentes participantes enriquece as discussões e contribui para o desenvolvimento profissional de todos.

Inicialmente, na pesquisa, ao refletir sobre como nos tornamos professores, verificamos que temas relacionados a ciências e matemática surgiram nas discussões. Por essa razão, no início do semestre, levantamos temas que os participantes queriam discutir e desenvolvemos atividades relacionadas a eles, elaboradas e realizadas pelos membros do grupo, indistintamente.

Devido a essa dinâmica que surgiu no grupo, realizamos junto com o professor, em parceria, pesquisa em que são gerados movimentos de aprendizagem marcados pelo questionamento, pela problematização, pela investigação e pela reflexão sobre as práticas escolares. O professor é também um produtor de conhecimentos que considera a investigação como centro em seu fazer docente e, portanto, ele deve ser protagonista da própria prática.

Nesse contexto, foram desenvolvidas atividades sobre o Minecraft, tema que surgiu da discussão sobre as tecnologias na Educação. Assim, temos como objetivo, neste relato de experiência, discutir algumas possibilidades da utilização do Minecraft na formação de professores dos anos iniciais, no que se refere à matemática.

Inicialmente, apresentaremos o referencial teórico que embasa nossas reflexões, seguido da descrição da experiência nesse grupo. Por fim, traremos algumas considerações. 


\section{Jogos eletrônicos na Educação}

A busca por uma Educação com significado não é tarefa simples, uma vez que perpassa por muitos sentidos e variáveis. Essa demanda começa antes do encontro do professor com os alunos no contexto da sala de aula, quando o educador reflete sobre o que será ensinado aos educandos. Como esse momento é essencial para definir como ocorrerão o ensino e a aprendizagem dos conteúdos, cria-se um leque de possibilidades por meio das "opções didáticas, metodológicas, atividades e organização do tempo e do espaço" (ITACARAMBI, 2013, p.15). Assim, a opção por uma proposta ou outra de ensino é capaz de interferir no desenvolvimento da autonomia, da cooperação e da participação social do estudante.

Concordamos com Silva et al. (2016) que o caráter austero com que a matemática, de forma recorrente, é apresentada em sala de aula torna-a dissociada da realidade do aluno. Esse fator acaba por empobrecer os conteúdos relacionados à disciplina, fazendo aumentar a dificuldade de aprendizagem do discente, o que os autores relacionam ao alto nível de reprovação e evasão escolar.

Ainda que se discuta acerca do uso de diferentes metodologias em sala de aula, é muito comum o ensino pautado em aulas expositivas e na concepção bancária de educação, que Paulo Freire (2011) caracteriza como o ato simplório de transferir, depositar no aluno valores e conhecimentos, sem que haja reflexão sobre eles e sem que sua força transformadora se expresse. Uma educação antagônica a essa foge da relação de alienação educador-educando e estimula a criticidade e a autonomia, sendo capaz de apresentar a matemática como significativa para a resolução de questões político-sociais.

Com a finalidade de romper com essa concepção "bancária" de ensino, é essencial considerar a aprendizagem como construção de conhecimento, pressupondo-se que o ato de conhecer está associado à significação. Isto é, dar significado a algo pressupõe realizar conexões entre esse algo e os demais conhecimentos já interiorizados pelo sujeito (ITACARAMBI, 2013), pois o ensino, em sua função no processo de construção de significados, deve relacionar o objeto em questão e os demais conhecimentos presentes no sujeito, sejam eles apreendidos com base

$$
\text { Periódico Horizontes - USF - Itatiba, SP-Brasil - e019015 }
$$


em suas experiências ou por meio do diálogo, mobilizando provocações em busca de novas reestruturações.

Em vista da necessidade de abordagens metodológicas diferenciadas, numerosas discussões são propostas com esse propósito, fazendo emergir diversas formas de alcançar a aprendizagem crítica e significativa. Dentre essas possibilidades, destacamos os jogos digitais que, por estarem imersos na vida das crianças e dos jovens, se tornam recursos educativos promissores.

Arruda (2011), por outro lado, considera que o lugar ocupado pelos jogos digitais contemporâneos suscita dúvidas acerca de sua importância na formação das novas gerações: uma das razões consiste no fato de as mídias, em geral, privilegiarem ações de violência, terror e competição extrema. Porém, o pesquisador afirma também que essas tecnologias reconfiguram o nosso olhar sobre o mundo e, uma vez que a criança já nasce nesse contexto, cabe à escola o desafio de valorizar essa cultura e criar condições de ensino e aprendizagem que levem em consideração o lugar que as tecnologias ocupam em suas vidas.

Corroboramos as considerações de Itacarambi (2013) a respeito do jogo em si que visto por meio da ótica pedagógica, ele é desafiador, pois permite a apresentação dos conteúdos de modo atrativo, o que favorece a criatividade na elaboração de estratégias e a persistência em busca de resultados.

No que tange ao trabalhar matemática na escola básica, Itacarambi $(2013$, p.21) afirma que "os jogos são um recurso para propor situações problema tanto numéricos como geométricos, pois permitem que esses sejam apresentados de modo atrativo e favorecem a criatividade na elaboração de estratégias de resolução ou de ganhar a partida". A autora ainda destaca a importância de o professor reconhecer que o jogo deve fazer parte do plano de ensino, diferenciando-o de um passatempo para preencher um horário vago de aula, por exemplo. Além disso, ele incorpora um componente metodológico valioso, passível de ser explorado de diversas formas.

Dentre as muitas plataformas de jogos existentes, discutiremos, neste relato, sobre o 
Minecraft, jogo eletrônico do tipo sandbox ${ }^{5}$ que permite ao jogador se movimentar livremente em um mundo virtual, sendo dada a ele maior flexibilidade em suas ações, em comparação com outros jogos que possuem estrutura mais linear em sua jogabilidade.

O Minecraft envolve jogadores que interagem, criando, posicionando e quebrando vários tipos de blocos cúbicos em um ambiente tridimensional virtual. Assim, um jogador ou multijogadores podem construir estruturas e obras de arte em diversos mundos, por meio dos múltiplos modos do jogo 6 .

O Minecraft é interessante devido às possibilidades e à gama de interações que a pessoa pode experienciar nesse contexto, evidenciando seu potencial, pois lhe é oferecido um ambiente de múltiplas possibilidades e, por ser cooperativo, incentiva a colaboração e o pensamento coletivo, propicia liberdade de escolhas, insere conteúdos disciplinares em seu contexto, estimula a criatividade, além outros recursos (SCHIMIDT; SUTIL, 2015). É dessa forma que a reflexão crítica, que parte tanto do professor quanto do aluno, ganha lugar de evidência. Aqui discutiremos uma possível forma de utilização do jogo no contexto da sala de aula do Ensino Fundamental.

Sua utilização em aulas de matemática já é uma realidade. Pesquisas nacionais (BOITO, 2016; SILVA et al., 2016; SILVA, 2017; VIANA, 2017) e internacionais (BOS et al., 2014; FOERSTER, 2017) discutem sobre essa temática. Esses estudos possuem, como objeto de ensino, conceitos geométricos em geral, porém enfatizam a geometria espacial, as concepções algébricas, os padrões, as medidas, o perímetro, a área e o volume. A abrangência entre os alunos também é significativa, o que inclui turmas do 6o ano do Ensino Fundamental, do 1ㅇ e do 3ㅇ ano do Ensino Médio e da 3ạ , 5a e 6a série em turmas de escolas estadunidenses.

Tais pesquisas se baseiam em diversos pressupostos, como as mudanças tecnológicas que vêm ocorrendo na sociedade, reconhecendo a necessidade de uma metodologia diferenciada com a inserção das tecnologias digitais; a busca pela análise das potencialidades do jogo como mídia digital no ensino; a capacidade de contextualização e de aprofundamento no ensino dos conteúdos; o desenvolvimento de raciocínio espacial por meio da tecnologia digital; a exploração

\footnotetext{
${ }^{5}$ Estilo de jogo em que são colocadas apenas limitações mínimas para o personagem.

${ }^{6}$ Informações retiradas do site https://minecraft.gamepedia.com/Minecraft_Wiki, indicado na página oficial do jogo.
}

Periódico Horizontes - USF - Itatiba, SP-Brasil - e019015 
da matemática sem medo, por parte dos alunos, uma vez que se utiliza a tecnologia; a compensação do espaço de tempo que existe, nos Estados Unidos, entre o ensino de geometria plana no ensino primário inicial e a geometria analítica superior; e, por fim, a busca de enriquecimento do teor do tema ensinado.

Notamos, portanto, fortes indícios de rica usabilidade do jogo em aulas de matemática, dentre os quais os autores atestam sua importância e o contraste com as metodologias tradicionais, característica desse recurso, em específico.

\section{O Minecraft na formação de professores}

Os avanços tecnológicos e as mudanças no âmbito educacional movidos pela necessidade de contextualizar o ensino da matemática exigem do professor o uso de novas ferramentas e metodologias de ensino.

A discussão sobre a importância dos jogos no ensino da matemática surgiu a partir da demanda de estreitar os laços entre os conhecimentos teóricos e práticos e aproximar os alunos de sua realidade por meio dos jogos, tendo em vista que a utilização de atividades lúdicas nas aulas de matemática contribui para o desenvolvimento cognitivo.

Os jogos têm como objetivo, de modo geral, trazer entretenimento ao usuário, sem a necessidade de promover o ensino e a aprendizagem. Entretanto, o seu formato atrativo, lúdico e colorido faz com que os jogadores possam estruturar a aprendizagem por meio das interações com o jogo e com o ambiente que ele oferece, o que contribui para desenvolver a concentração, a atenção, o uso de estratégias, o raciocínio lógico, a curiosidade, a socialização, etc.

Nesse sentido, os jogos educacionais tornam-se grandes aliados do professor para desenvolver a aprendizagem e para despertar o interesse dos estudantes, buscando aproximar a vinculação afetiva das situações de ensino e aprendizagem (BARBOSA, 1998).

A partir dessas discussões em nosso grupo, surgiu a necessidade de estudos e da busca de ferramentas lúdicas que venham a contribuir com o ensino da matemática no contexto escolar. Os diálogos foram surgindo à medida que uma professora integrante do grupo de

$$
\text { Periódico Horizontes - USF - Itatiba, SP-Brasil - e019015 }
$$


estudos relatou a dificuldade de aprendizagem dos seus alunos e a facilidade deles no domínio das ferramentas tecnológicas, o que recomenda torná-las aliadas das práticas em sala de aula, como recurso facilitador no processo ensino e aprendizagem.

Segundo Starepravo (2009, p. 20), no caso do ensino da matemática,

[...] Se conseguirmos compreender o papel que os jogos exercem na aprendizagem de matemática, poderemos usá-los como instrumentos importantes, tornando-os parte integrante de nossas aulas de matemática. Mas, devemos estar atentos para que eles realmente constituam desafios. Para isso, devemos propor jogos nos quais as crianças usem estratégias próprias e não simplesmente apliquem técnicas ensinadas anteriormente.

Durante as discussões e as buscas de estratégias para o ensino de matemática por meio de jogos, houve relatos sobre as dificuldades estruturais das escolas na disposição de espaços, na disponibilidade e no funcionamento das mídias educacionais e tecnológicas, e o grupo conversou sobre os jogos que também podem ser desenvolvidos com materiais simples, reciclados e podem favorecer uma atividade lúdica que facilite a aprendizagem dos alunos, sem a utilização de recursos mais sofisticados.

Nesse sentido, o professor enfrenta diferentes dificuldades para utilizar jogos, incluindo os eletrônicos, em sua prática e precisa, segundo Grando (2004), assumir como uma opção esse trabalho e estar pautado em pressupostos metodológicos que estejam de acordo com o projeto pedagógico da escola. Dessa forma, é fundamental que ele domine o jogo que proporá para seus alunos e tenha claro qual é o objetivo e que conceitos e conteúdos matemáticos abordará para que não se torne apenas um "apêndice em sala de aula".

Além disso, outra dificuldade que o docente pode ter é com relação ao tempo gasto com o uso de um jogo ser maior que em aulas com quadro negro e giz, o que pode fazer com que deixe de abordar outros conteúdos (GRANDO, 2004), e seja questionado tanto pela direção escolar quanto pelos pais dos alunos.

Ainda para a autora, o professor também pode não ter acesso a materiais sobre a utilização de jogos no ensino; comprometer a ludicidade do jogo ao fazer intervenções constantes durante

$$
\text { Periódico Horizontes - USF - Itatiba, SP-Brasil - e019015 }
$$


seu uso; exigir que os alunos joguem acabando com a perspectiva voluntaria do jogo e não ter clareza de que nem todos os conteúdos precisam ser ensinados a partir de um jogo.

A partir dos questionamentos e das conversas acerca do trabalho com jogos, surgiu a temática do Minecraft aplicado ao ensino da matemática e das ciências no Ensino Fundamental, levando em conta o interesse apresentado pelas crianças, no cotidiano escolar, por jogos virtuais. A proposta inicial de trabalho com o Minecraft foi o estudo de textos sobre esse jogo a partir de experiências desenvolvidas no âmbito educacional, seguido da vivência de seu funcionamento pelos participantes do grupo e, posteriormente, a proposição de oficinas com sugestões de prática com o jogo em sala de aula na disciplina de matemática.

Inicialmente discutimos dois textos que tratavam dos potenciais usos educativos para o Minecraft: um deles abordava a relação do jogo com a matemática e o outro, com ciências.

Ao iniciarmos o planejamento da oficina, deparamo-nos com o fato de que os participantes não conheciam o Minecraft, então nos reunimos para aprender a jogar, conhecer melhor suas potencialidades e pensar em como seria elaborada essa oficina. Porém, durante as tentativas de aprender os comandos do jogo e entender seus objetivos, percebemos o quão difícil era e que não seria possível pensar em atividades didáticas com o Minecraft se, primeiramente, não aprendêssemos a jogar. Além disso, como ele não é gratuito, surgiu outra dificuldade: as escolas teriam que pagar para obtê-lo. A partir disso, pensamos em transpor o jogo para materiais manipuláveis de fácil acesso e construir uma simulação dele com caixinhas de remédios, de leite, de manteiga etc.

No entanto, uma das professoras sugeriu que seu filho poderia nos ensinar a jogar, pois a nossa tentativa de aprender sozinhos não obteve sucesso e precisávamos de alguém para nos dar algumas instruções. Portanto, decidimos realizar essa primeira oficina para tentar compreender um pouco e aprender a utilizar o Minecraft. Depois de três horas de explicações, demonstrações, perguntas e dúvidas, chegamos à conclusão de que seria preciso muito mais tempo para, de fato, conseguirmos jogar sozinhos.

Sabemos que, ao trabalhar jogos digitais em sala de aula, dificilmente o professor dominará a tecnologia melhor do que os alunos o fazem. Segundo Maltempi (2008, p.62), “[...] é

$$
\text { Periódico Horizontes - USF - Itatiba, SP-Brasil - e019015 }
$$


necessário que o professor reorganize e reflita sobre sua prática ao inserir tecnologias em sala de aula, o que demanda tempo e esforço do docente (além de recursos tecnológicos)".

Além disso, o professor pode aproximar-se dos alunos que sabem mais que ele e tornálos seus parceiros. Assim, todos serão coaprendentes nesse processo de ensino e aprendizagem da matemática. Isso confirma que o professor não é mais o detentor do conhecimento e, assim como o aluno, precisa estar sempre aprendendo, ou seja, deixa de ser a autoridade do saber e passa, muitas vezes, a ser aquele que menos sabe (PONTE, 2000).

Assim, para utilizar um jogo, o professor precisa conhecê-lo profundamente e ter clareza dos objetivos que quer alcançar com as atividades que pretende propor para seus alunos. Fazendo um paralelo com as tecnologias digitais, Ponte e Serrazina (1998) apontam que os professores precisam ter conhecimento das implicações sociais e éticas das tecnologias; saber avaliar e utilizá-las em situações de ensino e aprendizagem.

Diante das dificuldades e das limitações, planejamos transpor o jogo para algo que pudesse ser manipulado, com base em materiais de fácil acesso. Optamos, então, por construir ferramentas do jogo a partir de cubos e prismas retangulares. Para isso, dividimos os participantes em grupos de três a quatro pessoas e projetamos algumas ferramentas (Figura 1), de modo que cada grupo escolhesse e construísse uma delas.

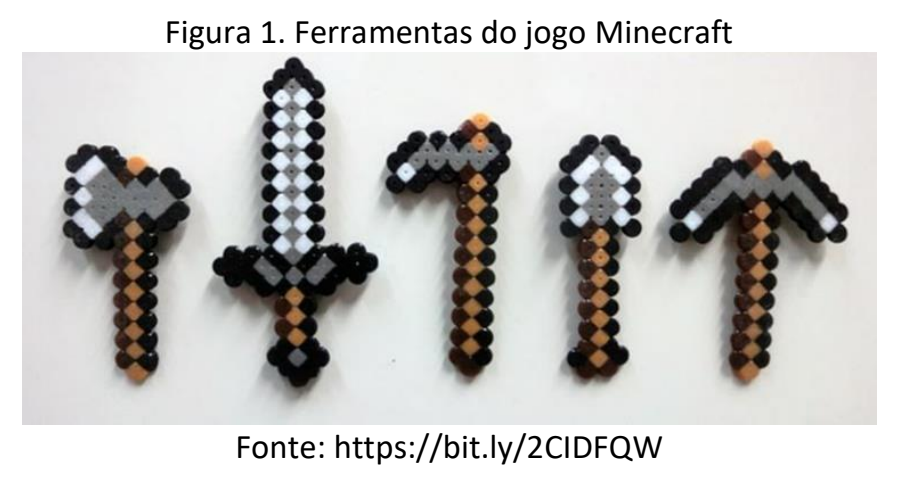

Imprimimos, em papel A4 e em cartolina - nas mesmas cores do jogo-, moldes dos cubos e dos prismas retangulares e entregamos um papel quadriculado para cada grupo planejar, inicialmente em duas dimensões, como desenhar a ferramenta escolhida (Figura 2).

$$
\text { Periódico Horizontes - USF - Itatiba, SP-Brasil - e019015 }
$$




\section{WSE HORIZONTES}

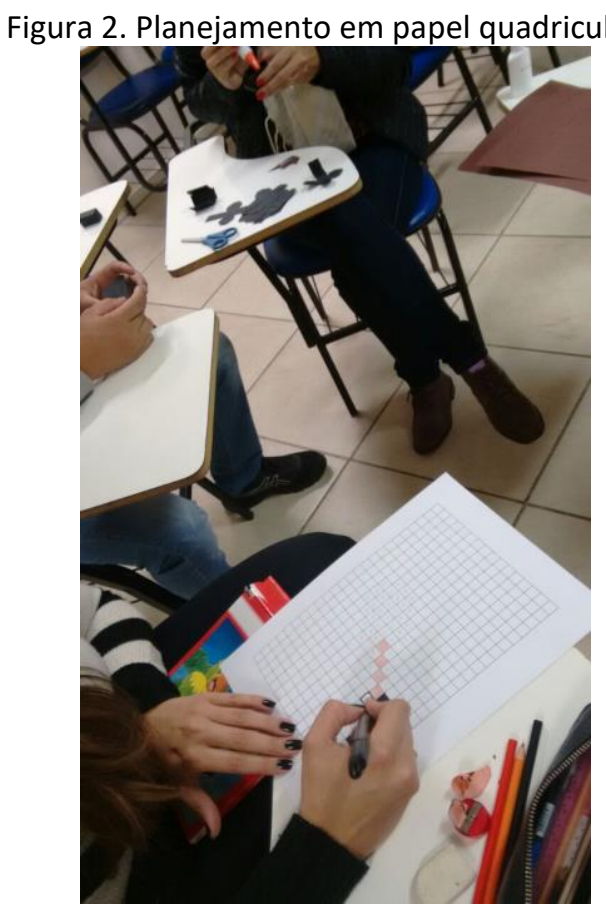

Fonte: Arquivos da pesquisa

Também entregamos moldes dos cubos e dos prismas retangulares nas mesmas cores do jogo, para posterior representação tridimensional da ferramenta. Enquanto um participante foi planejando a quantidade de sólidos necessários para representar a ferramenta, os demais foram cortando, colando e montando os cubos e os prismas (Figura 3).

Figura 3. Montagem da ferramenta

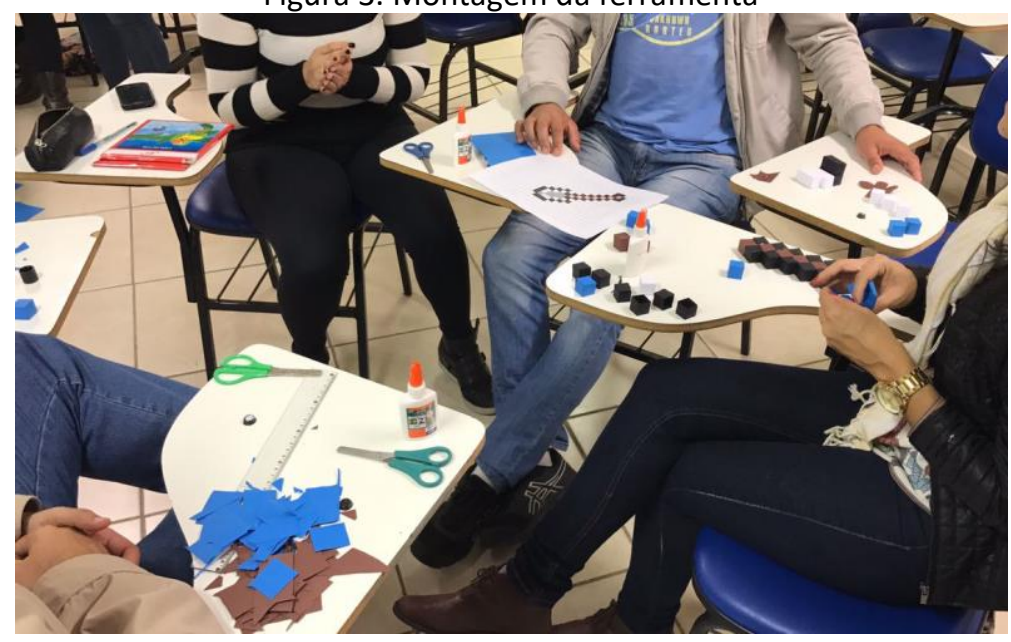

Fonte: Arquivos da Pesquisa

Periódico Horizontes - USF - Itatiba, SP-Brasil - e019015 
Ao final das três horas de oficina, um grupo conseguiu finalizar a ferramenta (Figura 4) e o outro, por falta de material, não conseguiu concluir. Destacamos aqui a importância de o professor planejar a quantidade de sólidos a ser utilizada, e de deixar alguns cubos e prismas prontos, pois as crianças necessitarão de mais tempo para a montagem das ferramentas. Esse aspecto evidencia que, mesmo o professor planejando com cuidado e atenção as aulas, nem sempre elas ocorrerão da maneira pretendida, o que demonstra a complexidade da sala de aula.

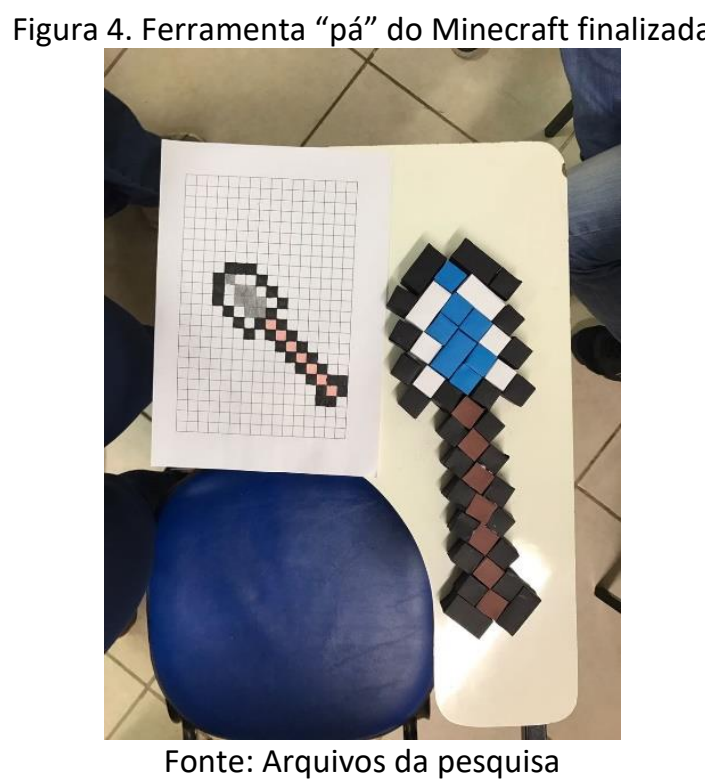

Um aspecto interessante com que nos deparamos nessa oficina refere-se à visualização. Os participantes tiveram que, observando uma imagem tridimensional projetada em um plano, construir sua representação também no plano, mas dessa vez no papel quadriculado; e, em seguida, elaborar tridimensionalmente, com os sólidos, a ferramenta escolhida.

Segundo Nacarato e Passos (2003, p.78), "em se tratando de situações de ensino de geometria a preocupação com a visualização é fundamental visto ser um dos elementos envolvidos no processo de representação". Essa atividade proposta na oficina possibilitou verificar que os grupos que não conseguiram construir a ferramenta podem ter apresentado alguma dificuldade em visualizar a imagem e representá-la.

Essa oficina permitiu promover também a aprendizagem e a exploração de outros Periódico Horizontes - USF - Itatiba, SP-Brasil - e019015 
conceitos matemáticos, como a planificação e a construção do cubo e do prisma. O professor pode também discutir sobre seus elementos - arestas, faces e vértices -, sobre a quantidade de sólidos necessários para construir as ferramentas, sobre a utilização da régua, a área e o volume, a escala etc.

\section{Algumas considerações}

Os assuntos abordados e discutidos durante o grupo de pesquisa e extensão de práticas docentes em ciências e matemática exerceram grande influência no modo como os professores iniciantes realizavam a mediação do ensino das disciplinas supracitadas: passaram a pautar a aprendizagem dos alunos em questionamentos, levantamento de hipóteses e problematizações acerca dos objetivos a alcançar com o que se pretende ensinar. Além disso, sabemos que nenhum currículo consegue dar conta de todos os conhecimentos e habilidades de que um professor precisa para atuar. Logo, é necessário estar em constante formação para construir permanentemente seus saberes e acumular experiências pedagógicas.

A interação entre estudantes, professores e pesquisadores de diversas áreas do conhecimento, como Matemática, Química e Pedagogia, em seus diferentes contextos e olhares, contribui para importantes discussões e para o levantamento de temas também relevantes, enriquecendo nossas práticas docentes nos anos iniciais.

Por meio dos estudos e das oficinas realizadas, foi possível evidenciar a importância da utilização dos jogos nas aulas de ciências e matemática, tendo em vista seu grande potencial de geração de conhecimento. Por meio do seu caráter lúdico e atrativo, é possível desenvolver habilidades, como o uso de estratégias para resolução de problemas, a concentração, a atenção, a socialização, a criatividade, entre outras.

Ao estruturarmos o planejamento das oficinas, a principal dificuldade observada foi que os professores participantes não tinham o domínio da ferramenta de objeto de estudo, nesse caso, o jogo Minecraft. E este foi o nosso primeiro desafio: compreender a ideia do jogo, saber manuseá-lo minimamente, mas tendo em mente que os alunos que estão inseridos nesse

$$
\text { Periódico Horizontes - USF - Itatiba, SP-Brasil - e019015 }
$$


universo tecnológico dominam as tecnologias digitais com muito mais facilidade que nós, aprendizes.

O segundo desafio foi analisar as potencialidades desse jogo para o ensino de matemática. Assim sendo, foi preciso refletir, planejar e discutir com os professores o uso das ferramentas tecnológicas, de modo que eles pudessem auxiliá-los em suas práticas pedagógicas e no processo ensino e aprendizagem nas aulas de matemática, tornando-as significativas para os alunos.

A dificuldade apontada sinalizou para o grupo a necessidade da formação continuada dos professores, que precisam buscar aprimorar-se no uso das ferramentas tecnológicas, pois, muitas vezes, colocam-se na condição de coaprendentes, em virtude de o aluno apresentar um domínio das tecnologias muito maior que o seu. Ao apresentarmos essa situação de coaprendizagem, encontramos também um aspecto positivo no fato de o professor assumir a condição de aprendiz: ele deixa de ser autoridade do saber e estabelece uma maior aproximação com os alunos (PONTE, 2000).

O trabalho com o Minecraft permitiu-nos promover e explorar conceitos matemáticos diversos, como a planificação e a construção de sólidos geométricos (cubo e prisma), destacando os elementos dos sólidos como vértices, arestas e faces, além de permitir abordar a quantidade de sólidos necessários para a construção das ferramentas do jogo, a utilização da régua e dos conceitos de área e volume.

Além disso, foi necessária uma representação mental, quando os participantes tiveram que planejar a ferramenta em três dimensões - a partir da sua projeção em um plano de duas dimensões, como no papel quadriculado - e, em seguida, elaborar e construir essa ferramenta escolhida com os sólidos geométricos. Esse desafio pode estimular os alunos em suas representações e elaborações mentais, para além das habilidades já mencionadas. Isso confirma a importância da visualização em geometria, de modo que os alunos possam representar um objeto tanto no plano bidimensional quanto no tridimensional.

Diante do exposto, destacamos que é de suma importância a parceria entre UniversidadeEscola, por meio de projetos de extensão. As pesquisas sobre ensino devem ser realizadas junto

$$
\text { Periódico Horizontes - USF - Itatiba, SP-Brasil - e019015 }
$$


com os professores da Educação Básica, sem ficar aprisionadas em estantes acadêmicas, mas sim compartilhadas e divulgadas, de forma a colaborar coletivamente com a construção de uma educação de qualidade para todos.

\section{Referências}

ARRUDA, E. P. Aprendizagens e jogos digitais. 1. ed. Campinas, SP: Alínea, 2011.

BARBOSA, L. M. S. Projeto de trabalho: uma forma de atuação psicopedagógica. 2. ed. Curitiba: L. M. S., 1998.

BOITO, P. Jogo computacional: um aliado para a aprendizagem da matemática. In: Encontro Brasileiro de Estudantes de Pós-Graduação em Educação Matemática. 20., Curitiba, 2016. Anais [...] Curitiba, 2016.

BOS, B. et al. Learning mathematics through Minecraft. Teaching Children Mathematics, Virginia, v.21, n.1, p.56-59, 2014.

FOERSTER, K. T. Teaching spatial geometry in a virtual world: using Minecraft in mathematics in grade 5/6. In: GLOBAL ENGINEERING EDUCATION CONFERENCE, 2017, Atenas. Anais [...] Atenas, 2017.

FREIRE, P. Pedagogia do oprimido. 50. ed. São Paulo: Paz e Terra, 2011.

GRANDO, R. C. O jogo e a matemática no contexto da sala de aula. 1. ed. São Paulo: Paulus, 2004.

ITACARAMBI, R. R. O jogo como recurso pedagógico para trabalhar matemática na escola básica: ensino fundamental. 1. ed. São Paulo: Livraria da Física, 2013.

MALTEMPI, M. V. Educação matemática e tecnologias digitais: reflexões sobre prática e formação docente. Acta Scientiae, Canoas, v.10, n.1, p.59-67, 2008.

NACARATO, A. M.; PASSOS, C. L. B. A geometria nas séries iniciais: uma análise sob a perspectivada prática pedagógica e da formação de professores. 1. ed. São Carlos: EdUFSCar, 2003.

PONTE, J. P. Tecnologias de informação e comunicação na formação de professores: que desafios? Revista Iberoamericana de Educação, n.24, p.63-90, 2000. Disponível em: http://www.rieoei.org/rie24a03.htm. Acesso em: 18 out. 2007.

$$
\text { Periódico Horizontes - USF - Itatiba, SP-Brasil - e019015 }
$$


PONTE, J. P.; SERRAZINA, L. As novas tecnologias na formação inicial de professores. 1998. Disponível em: http://www.dapp.minedu.pt/nonio/estudos/formacao_inicial.pdf. Acesso em: 24 jul. 2005.

SCHIMIDT, D. A. T.; SUTIL, N. Explorando o ambiente virtual do Minecraft em sala de aula: potencialidades do jogo para trabalhar a interação do ser humano com o ambiente. In: Congresso Internacional de Tecnologia na Educação, 13., 2015, Olinda. Anais [...] Olinda, 2015.

SILVA, A. L. et al. A utilização do Minecraft na construção de conceitos geométricos como forma de estímulo à aprendizagem da matemática. In: CONGRESSO NACIONAL DE EDUCAÇÃO, 3., 2016, Natal. Anais [...] Natal, 2016.

SILVA, H. W. Estudos sobre as potencialidades do jogo digital Minecraft para o ensino de proporcionalidade e tópicos de geometria. 2017. 113 f. Dissertação (Mestrado em Educação Matemática) - Pontifícia Universidade Católica de São Paulo, São Paulo, 2017.

STAREPRAVO, A. R. Jogando com a matemática: números e operações. 1. ed. Curitiba: Aymará, 2009.

VIANA, L. H. O Minecraft no processo de ensino e aprendizagem da geometria espacial da posição. 2017. 75 f. Trabalho de Conclusão de Curso (Graduação em Matemática) Universidade Estadual da Paraíba. Campina Grande, 2017.

\section{AGRADECIMENTOS}

O apoio da FAPEMIG (CHE APQ 00771-14) e da PROEX da UFJF.

Recebido em dezembro de 2017.

Aprovado em fevereiro de 2018.

Periódico Horizontes - USF - Itatiba, SP-Brasil - e019015 